\title{
GERENCIAMENTO DE RESULTADOS CONTÁBEIS E SUAS IMPLICAÇÕES NO DIREITO TRIBUTÁRIO: UMA ANÁLISE DAS PESQUISAS REALIZADAS NO \\ BRASIL ENTRE OS ANOS DE 2013 E 2017
}

\author{
MANAGEMENT OF ACCOUNTING INCOME AND ITS IMPLICATIONS IN TAX \\ LAW: AN ANALYSIS OF THE RESEARCH CARRIED OUT IN BRAZIL BETWEEN \\ 2013 AND 2017
}

\author{
Valquíria Duarte Vieira Rodrigues ${ }^{1}$ \\ Luciano Pineli Chaveiro ${ }^{2}$
}

\begin{abstract}
Mestrando no Programa de Mestrado Acadêmico em Planejamento e Desenvolvimento Regional da UNITAU Universidade de Taubaté/SP. Pós Graduado em Direito Empresarial pela Fundação Getúlio Vargas - FGV/Rio. Advogado e Professor da Universidade Estadual do Tocantins - UNITINS. Rua 03 n 881, Setor Oeste, GoiâniaGO. CEP: 74.115-050. E-mail: lucianopineli @ terra.com.br
\end{abstract}

Mestranda no Programa de Mestrado Acadêmico em Agronegócio da Universidade Federal de Goiás. Pós graduada em Gestão Empresarial pela Universidade Salgado de Oliveira. Bacharel em Ciências Contábeis. Professora na Universidade Estadual de Goiás - UEG, Campus Jaraguá-GO. Rua 03, n 25, Vila Rio Vermelho, Jaraguá - Goiás. CEP. 76.330-000. E-mail:prof.valquiriaduarte@ gmail.com.

\section{RESUMO}

Este estudo teve como objetivo analisar as publicações divulgadas no Brasil sobre Gerenciamento de Resultados Contábeis entre 2013 a 2017. A metodologia utilizada foi exploratória de natureza quantitativa e descritiva. As análises foram realizadas por meio de estatística descritiva e por meio de análise de conteúdo. Os resultados obtidos apresentaram

\footnotetext{
${ }^{1}$ Mestranda no Programa de Mestrado Acadêmico em Agronegócio da Universidade Federal de Goiás. Pós graduada em Gestão Empresarial pela Universidade Salgado de Oliveira. Bacharel em Ciências Contábeis. Professora na Universidade Estadual de Goiás - UEG, Campus Jaraguá-GO. Rua 03, nº 25, Vila Rio Vermelho, Jaraguá - Goiás. CEP. 76.330-000. E-mail:prof.valquiriaduarte@gmail.com.

${ }^{2}$ Mestrando no Programa de Mestrado Acadêmico em Planejamento e Desenvolvimento Regional da UNITAU Universidade de Taubaté/SP. Pós Graduado em Direito Empresarial pela Fundação Getúlio Vargas - FGV/Rio. Advogado e Professor da Universidade Estadual do Tocantins - UNITINS. Rua 03 nº 881, Setor Oeste, GoiâniaGO. CEP: 74.115-050. E-mail: lucianopineli @ terra.com.br
} 
que houve um aumento no número de pesquisas sobre o tema nos três últimos anos, mais de 70\% de publicações nos anos de 2015 a 2017 e percebeu-se também a existência de uma centralização da produção dos artigos em apenas quatro autores, o que representa mais de $65 \%$ da produção.

PALAVRAS-CHAVE: Informação Contábil. Gerenciamento de Resultados Contábeis. Tomada de decisão. Demonstrações financeiras. Direito tributário. Análise Bibliométrica.

\begin{abstract}
This study aimed to analyze the publications published in Brazil on Accounting Results Management between 2013 and 2017. The methodology used was exploratory quantitative and descriptive. Analyzes were performed using descriptive statistics and content analysis. The results showed that there has been an increase in the number of researches on the subject in the last three years, more than $70 \%$ of publications from 2015 to 2017 and it was also noticed the existence of a centralization of article production in only four authors., which represents over $65 \%$ of production.
\end{abstract}

KEYWORDS: Accounting Information. Accounting Results Management. Decision making. Financial statements. Tax law. Bibliometric analysis.

\title{
1 INTRODUÇÃO
}

Um dos objetivos da contabilidade é subsidiar os gestores na tomada de decisão, podendo, desta maneira, contribuir para o desempenho da empresa e auxiliar os usuários das demonstrações financeiras fornecendo informações fidedignas e confiáveis. (MARIN 2014). Esse subsídio se dá através das informações financeiras pelos demonstrativos. Quando se usa essa informação de maneira pessoal, de forma a obter algum benefício, torna ela não confiável. Segundo Rodrigues (2013), a manipulação de informações contábeis, que para alguns é uma prática aceita e para outros não, quando utilizada com finalidades escusas, 
torna-se um sério problema para a contabilidade.

Gerenciamento de Resultados (Earnings Management) é um conjunto de técnicas, que utiliza de procedimentos contábeis previstos na lei, mas que resultam na apresentação dos resultados da organização de acordo com os objetivos particulares dos agentes da empresa, de forma que as informações contábeis, em certos casos, deixam de retratar a realidade do negócio (PAULO; LEME, 2009; MARTINEZ, 2006; REZENDE; NAKAO, 2012; RODRIGUES, 2007).

Podemos dizer, resumidamente, que gerenciamento de resultados significa uma alteração no resultado contábil visando alguma motivação particular. Na visão de Martinez (2001), é crucial entender que, gerenciamento dos resultados contábeis, não é fraude contábil, ou seja, opera-se dentro dos limites do que prescreve a legislação contábil.

Os autores Amat e Gowthorpe (2004), esclarecem que o gerenciamento de resultados implica a alteração do resultado financeiro empregando escolhas contábeis, estimativas e outras práticas permitidas pela regulamentação contábil. Já para Santos e Grateron (2003, p. 11), qualquer manipulação da informação contábil que contenha uma distorção na conformação correta desta, deve ser entendida como uma espécie de fraude.

Para Martins et. al (2016), a existência de critérios múltiplos nas normas e práticas contábeis possibilita aos administradores e contadores, escolher alternativas válidas com o objetivo de apresentarem informações desejadas, impactando o desempenho ou estrutura financeira da empresa. Nesse sentido a transparência das informações contábeis publicadas pelas empresas torna-se requisito essencial para que os usuários tenham a garantia de estarem referenciando suas decisões em relatórios confiáveis. (Matsumoto; Parreira, 2007).

De acordo com Coelho e Lima (2009), o gerenciamento de resultados na perspectiva dos gestores das empresas pode apresentar apenas a lógica de decidir qual lucro reportar, considerando a premissa de que não estão forjando evidências ou efetivando fraudes, ou seja, entendendo que eles estão somente antecipando ou retardando o reconhecimento de receitas e despesas, dentro do intervalo de manobra permitido pelos padrões contábeis vigentes. Entretanto, a prática de gerenciar os resultados, quando feita de forma arbitrária, pode comprometer a transparência das informações apresentadas pela empresa.

Para Matsumoto et.al (2007), o gerenciamento de resultados contábeis nas empresas é um problema real, sobretudo por encontrar refúgio na flexibilidade das normas e 
regulamentos contábeis, que permitem alternativas distintas para a contabilização de um mesmo evento contábil. E mesmo, onde há regras, estas facultam ao gerente escolhas distintas sobre a aplicação dessas regras.

O gerenciamento de resultados é um tema novo e que vem sendo pouco divulgado no Brasil por esse motivo o presente trabalho justifica-se, uma vez que tem como objetivo geral fazer uma análise dos artigos publicados entre os anos de 2013 a 2017 no Brasil, em relação ao tema gerenciamento de resultados contábeis, baseando-se nos periódicos da área de contabilidade, e tendo como objetivos específicos: (I) relatar a informação contábil; (II) apresentar o conceito de gerenciamento de resultado contábil, segundo diversos autores; (III) realizar um estudo bibliométrico das publicações analisadas.

A pesquisa classifica-se como exploratória descritiva e quantitativa. A coleta de dados foi feita em artigos sobre gerenciamento de resultados, os quais foram selecionados através de ferramentas de busca nos sítios dos dez principais periódicos de contabilidade do país. O artigo está dividido em 5 títulos, sendo o primeiro a introdução, o segundo a fundamentação teórica, terceiro metodologia, quarto análise de dados e quinto as considerações finais seguido das referências.

\section{FUNDAMENTAÇÃO TEÓRICA}

\subsection{Informação Contábil}

A Contabilidade tem como um de seus principais objetivos, prestar informações úteis sobre as entidades aos seus diversos usuários, visto que é direcionada ao público geral. Entretanto, os usuários não escolhem diretamente os critérios de mensuração e/ou evidenciação contábil. O que para Paulo (2007), a qualidade da informação contábil esteja fortemente relacionada ao ambiente econômico, político e social em que a firma estiver inserida.

Segundo o CPC (2008, p.16-22), as características qualitativas das informações contábil-financeira útil, identificam os tipos de informação que muito provavelmente são reputadas como as mais úteis para os investidores, credores por empréstimos e outros credores, existentes e em potencial, para tomada de decisões a cerca da entidade que reporta 
com base na informação contidas nos seus relatórios contábil-financeiros (informação contábil-financeira).

Para Coelho e Niyama (2011), a qualidade da informação dos resultados contábeis significa nada mais que a qualidade da informação dos relatórios contábeis, pois afirma que a qualidade será mais quanto menor tiver sido a manipulação dos resultados, destacando a importância da transparência na divulgação das informações contábeis.

Segundo a NBC TG (Normas Brasileiras de Contabilidade Técnica-Gerais) Estrutura Conceitual, a informação precisa concomitantemente ser relevante e representar com fidedignidade a realidade reportada, para ser útil. Nem a representação fidedigna de fenômeno irrelevante, tampouco a representação não fidedigna de fenômeno relevante, auxilia os usuários a tomarem boas decisões.

Para Paulo (2007), normalmente quando se discute a qualidade das informações contábeis ou qualidade dos resultados, considera-se que existe uma básica qualidade quando os relatórios contábeis são manipulados. Mas observa-se que em muitos casos, os problemas da qualidade da informação contábil estão relacionados ao excessivo montante dos itens não recorrentes publicados ou falta de transparência, mesmo quando as escolhas contábeis foram realizadas em concordância com as normas contábeis vigentes.

Por fim Paulo (2007) afirma ainda que a informação contábil é influenciada por critérios alternativos de mensuração e evidenciação, conhecidos por "escolhas contábeis", facultando ao gestor a escolha entre normas e práticas permitidas pela regulação vigente. Portanto o conceito de qualidade de informação contábil torna-se complexo e dependendo do objetivo de seu usuário.

\subsection{Gerenciamentos de resultado contábil}

O gerenciamento de resultado contábil vem sendo discutido com mais frequência nos últimos anos, tendo pontos de vista distintos de diferentes autores como, Goulart (2007), que o gerenciamento de resultado pode ser entendido como um conjunto de ações intencionais, por parte dos preparadores de demonstrações financeiras, com impacto sobre a representação contábil da entidade, dentro dos limites permitidos pelas normas e padrões contábeis, tendo 
em vista o atendimento de interesse dos gestores da organização objeto da divulgação financeira.

Segundo Martinez (2001) o gerenciamento é definido como escolhas permitidas ao gestor da empresa, que tomara suas decisões conforme lhe seja útil. Sendo o gerenciamento de resultados contábeis caracterizado como escolhas discricionárias facultadas ao gerente pelas normas contábeis. Assim, pelo uso do julgamento, o gestor realiza suas escolhas em razão dos incentivos que o levam a reportar um resultado distinto daquele ditado pela realidade concreta dos negócios.

Já para Cosenza e Grateron (2003) a contabilidade criativa, termo que utiliza para se referir á expressão "earnings management", é uma forma de maquiagem da realidade patrimonial de uma entidade, realizada por meio da manipulação intencional das informações contábeis, com o objetivo de apresentar uma imagem desejada pelos gestores.

Martinez (2001) considera que essa alteração proposital dos resultados contábeis é exercida dentro de um âmbito legal da discricionariedade das normas e práticas contábeis. Porém Iudícibus (2003) discorda dessa afirmativa, pois segundo ele é necessário procurar diferenciar o termo contabilidade criativa, comumente relacionada com a prática de manipulação de resultado, da contabilidade conduzida e vivida pelo espírito inovador.

O tema teve seu destaque quando as empresas de grande porte como WorldCom, Enron e Tyco incorreram em fraudes contábeis que escandalizaram o mercado e expuseram seus acionistas a enormes perdas patrimoniais (ROSA et al., 2010). A partir de então, ficou especialmente ligado a prática oportunistas dos gestores visando os benefícios próprios em detrimento dos interesses dos acionistas (JIRAPORN et al., 2008).

\subsubsection{Motivações para utilizar o gerenciamento de resultado}

Martinez (2001) classifica as motivações em três tipos: (1) Motivações Vinculadas ao Mercado de Capitais; (2) Motivações Contratuais e (3) Motivações Regulamentares e Custos Políticos, o autor explica ainda que pelo que foi observado, quanto a motivação, o gerenciamento de resultado contábil, pode ter como objetivos: i) minimização de custos políticos, ii) maximização da riqueza dos gestores ou iii) minimização do custo de capital. 
Além dos incentivos econômicos e financeiros, pode se considerar que existam motivações psico-sociais para que os administradores tenham comportamento oportunístico. Paulo (2007), o autor salienta que apesar de, os administradores serem julgados e recompensados pela qualidade das informações contábeis divulgadas, eles sofrem pressões ambientais na empresa, como, por exemplo, atingir lucros estabelecidos, ampliar a participação do mercado consumidor, superar os concorrentes diretos, etc.

Para Dechow et al. (1996), uma importante motivação para o gerenciamento de resultado é o desejo de obter financiamento externo a baixo custo, e que as empresas experimentam significativos aumentos em seus custos de capital quando o GR (Gerenciamento de Resultados) se torna público.

Matsumoto et al (2007) em uma adaptação de Martinez (2001), cita que seriam três grupos de motivações, como apresentado no quadro 2 abaixo, que exemplificam as causas sobre as quais repousam as intenções do gerente, no momento em que decide optar pelo gerenciamento de resultados.

\begin{tabular}{|c|c|c|}
\hline Muliszole & Objolives porais & Obictings aperificos \\
\hline $\begin{array}{l}\text { Motivales } \\
\text { vinculates } 20 \\
\text { Morado de } \\
\text { Cuptais }\end{array}$ & 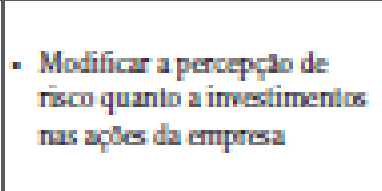 & 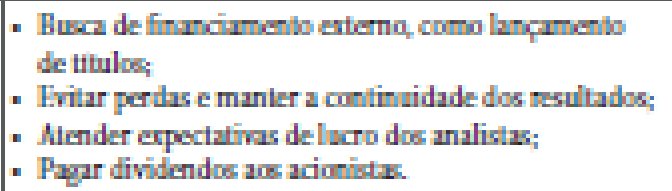 \\
\hline $\begin{array}{l}\text { Motiveple } \\
\text { conlnhturis }\end{array}$ & 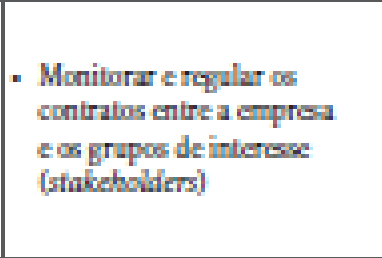 & 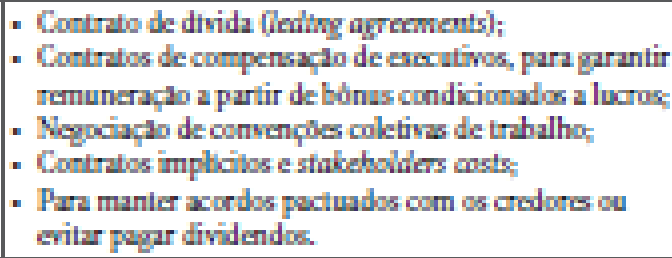 \\
\hline 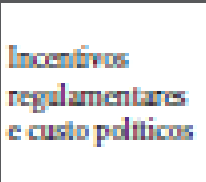 & 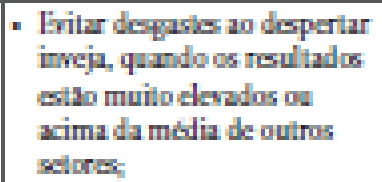 & 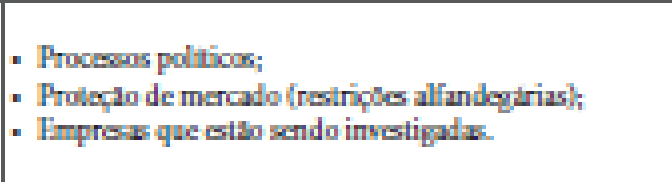 \\
\hline
\end{tabular}

Matsumoto et al (2007) diz também que fica evidente que as causas estão ligadas à continuidade do empreendimento, o que é importante para o usuário pelo ponto de vista do investimento realizado e retorno esperado mesmo. Nesse aspecto o gerenciamento é crucial, pois protege o usuário investidor, transferindo para períodos posteriores o ganho ou a perda 
pela prática da manipulação contábil.

Nota-se que tais motivações para utilizar o gerenciamento de resultados, se colocadas em práticas não condizem a real situação da entidade. Percebe-se que o gerenciamento de resultado envolve ações dos gestores com propósito de alterar as informações divulgadas sobre a empresa, Goulart (2007).

\section{METODOLOGIA (material e métodos)}

O presente trabalho classifica-se como exploratório, porque se trata de uma busca mais próxima da realidade do tema. Segundo Cassel e Symon (1994), a pesquisa exploratória visa elucidar um tópico ainda pouco abordado na literatura.

Sendo de natureza quantitativa e descritiva, pois usa de dados coletados que serão analisados e interpretados. Por sua vez a pesquisa descritiva tem como objetivo principal descrever as características de determinada população ou fenômeno, (GIL, 1996), e por fim a pesquisa quantitativa pode ser entendida como a que utiliza um instrumental estatístico para a análise de um problema, ou seja, atém-se a medir unidades ou categorias (OLIVEIRA, 1988).

Para o desenvolvimento da pesquisa buscou-se o periódico Contabilidade no site A Coordenação de Aperfeiçoamento de Pessoal de Nível Superior - CAPES, (www.capes.gov.br). Destacam-se no quadro 1, a seleção dos periódicos escolhidos, sendo eles 10 periódicos na área da contabilidade, foram escolhidos artigos publicados em português, que possuíam pelo menos um artigo publicado sobre o tema gerenciamento de resultados, no período de janeiro de 2013 a dezembro de 2017. Foi escolhido esse período de cinco anos para que a pesquisa pudesse ser mais ampla, porque se fosse escolhido um período menor não teria dados suficientes para se fazer a análise, e assim obter um entendimento de como vem sendo feita a divulgação e as publicações referentes ao tema Gerenciamento de Resultados Contábeis no Brasil.

Quadro 1: Periódicos de contabilidade selecionados e estudados na pesquisa

\begin{tabular}{|l|l|l|}
\hline PERIODICO & ISSN & SIGLA \\
\hline Revista de Administração e Contabilidade da Unisinos & $1984-8196$ & RACU \\
\hline
\end{tabular}




\begin{tabular}{|l|l|l|}
\hline Contabilidade Vista \& Revista & $0103-734 X$ & CVR \\
\hline Revista de Administração, Contabilidade e Economia & $1678-6483$ & RACE \\
\hline Revista de Contabilidade da UFBA & $1984-3704$ & RC-UFBA \\
\hline Revista de Contabilidade e Finanças & $1519-7077$ & RC\&F \\
\hline Revista Contemporânea de Contabilidade & $2175-8069$ & RCC \\
\hline Revista Contabilidade e Controladoria & $1984-6266$ & RC\&C \\
\hline $\begin{array}{l}\text { Revista de Contabilidade do Mestrado de Ciências Contábeis } \\
\text { da UERJ }\end{array}$ & $1984-3291$ & RCM \\
\hline Revista de Contabilidade e Organizações & $1982-6486$ & RCO \\
\hline Revista Universo Contábil & $1809-3337$ & RUC \\
\hline
\end{tabular}

Fonte: CAPES (2018)

Depois de identificar os periódicos, buscou-se em cada um dos sites a ferramenta de busca ou pesquisa, usando a palavra-chave: "gerenciamento de resultados", e nas opções de pesquisa a data de busca, que foi entre o período de janeiro de 2013 a dezembro de 2017. Selecionou-se apenas os artigos com o título que continha o tema gerenciamento de resultados. Sendo identificados 27 artigos.

Para facilitar a análise dos dados coletados sobre os artigos selecionados, usou-se o software Microsoft Office Excel 2007, analisados através de estatística descritiva, segundo o autor Ferreira (2005), a estatística descritiva tem como objetivo a descrição dos dados, sejam eles de uma amostra ou de uma população, (apresentada na sessão 4 deste artigo).

Em seguida, com base nos dados foi feita a análise bibliométrica dos artigos selecionados. Para Macedo et al. (2009, p. 92) os estudos bibliométricos são importantes para conhecer o estágio em que a pesquisa se encontra em uma determinada área. No final desenvolveu-se uma medida bibliométrica, para classificação dos autores com base nas quantidades de publicações.

\section{ANÁLISE DE DADOS}

Inicialmente foi feito a análise por meio da estatística descritiva, dos artigos selecionados, baseando-se nos periódicos utilizados na pesquisa, em seguida apresenta-se uma 
análise bibliométrica da produção do gerenciamento de resultados.

\subsection{Análise descritiva dos artigos}

Na tabela 1 é apresentada a quantidade de artigos que foram analisados na pesquisa, também mostrado graficamente os mesmos no gráfico 1. Referente à tabela 1 pode-se observar que em 2013, o ano base da pesquisa, até 2017, teve um aumento na quantidade de artigos publicados por ano, sendo que no ano de 2013 e 2014 foram publicados quatro artigos a cada ano, assim no ano de 2015 e 2016 teve um aumento de 1 artigo a mais, sendo 2015 cinco e 2016 seis artigos, em 2017 ouve um aumento de dois artigos finalizando-se com oito artigos.

Conclui que houve um aumento nas publicações de artigos entre 2015 a 2017, isto se comparado a 2013 e 2014 que se manteve a mesma quantidade de publicações. Observa-se que entre os periódicos estudados em questão, dois deste (RC\&F e RUC), apresentou mais de $40 \%$ dos artigos publicados (11 artigos no total). Nos 5 anos analisados mais de $70 \%$ da produção foi publicado nos últimos três anos.

Tabela 1: Números de artigos analisados por ano e por periódico selecionado

\begin{tabular}{lccccccc}
\hline Periódico & 2013 & $\mathbf{2 0 1 4}$ & $\mathbf{2 0 1 5}$ & $\mathbf{2 0 1 6}$ & $\mathbf{2 0 1 7}$ & Total & $\%$ \\
\hline RACU & - & - & $\mathbf{1}$ & - & - & $\mathbf{1}$ & 3,7 \\
\hline CVR & $\mathbf{1}$ & - & - & - & - & $\mathbf{1}$ & 3,7 \\
\hline RACE & - & - & - & - & $\mathbf{1}$ & $\mathbf{1}$ & 3,7 \\
\hline RC-UFBA & - & - & - & $\mathbf{2}$ & $\mathbf{1}$ & $\mathbf{3}$ & 11,11 \\
\hline RC\&F & $\mathbf{1}$ & - & $\mathbf{1}$ & $\mathbf{2}$ & $\mathbf{2}$ & $\mathbf{6}$ & 22,24 \\
\hline RCC & - & $\mathbf{1}$ & $\mathbf{1}$ & - & $\mathbf{1}$ & $\mathbf{3}$ & 11,11 \\
\hline RC\&C & - & - & $\mathbf{1}$ & - & - & $\mathbf{1}$ & 3,7 \\
\hline RCM & $\mathbf{1}$ & $\mathbf{2}$ & - & - & - & $\mathbf{3}$ & 11,11 \\
\hline RCO & $\mathbf{1}$ & $\mathbf{1}$ & - & $\mathbf{1}$ & - & $\mathbf{3}$ & 11,11 \\
\hline
\end{tabular}




\begin{tabular}{llllllll}
\hline RUC & - & - & $\mathbf{1}$ & $\mathbf{1}$ & $\mathbf{3}$ & $\mathbf{5}$ & 18,52 \\
& & & & & & & \\
\hline Total & 4 & 4 & $\mathbf{5}$ & $\mathbf{6}$ & $\mathbf{8}$ & $\mathbf{2 7}$ & $\mathbf{1 0 0 , 0 0}$ \\
\hline
\end{tabular}

Fonte: Elaborada pelos autores de acordo com os dados obtidos pela pesquisa / 2018.

Gráfico 1: Números de artigos analisados por ano e por periódico selecionado

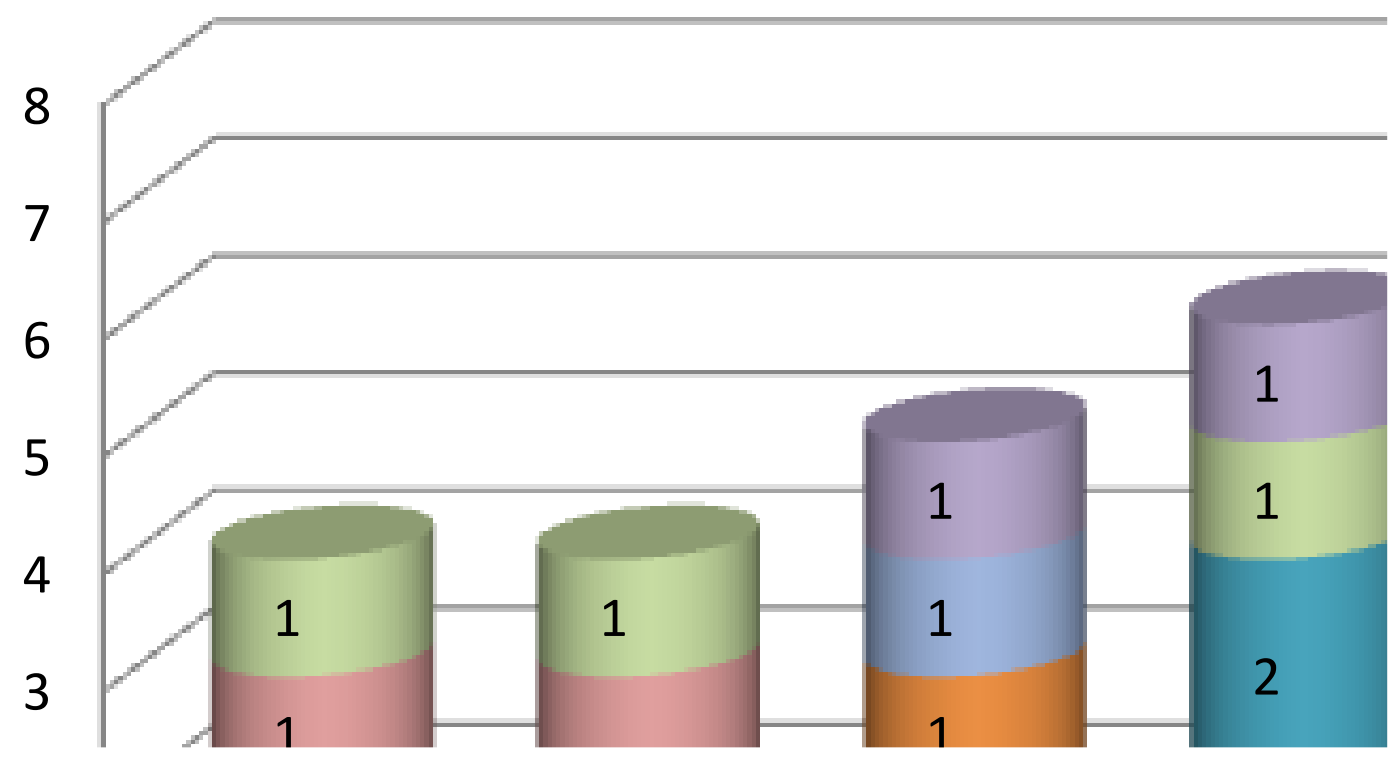

Fonte: Elaborada pelos autores de acordo com os dados obtidos pela pesquisa / 2018.

Na tabela 2 contém a classificação dos estudos em empíricos e teóricos, nota-se que os estudos empíricos sobressaem aos teóricos. Em muitos deles foram usados formulas as quais visa desenvolver seus trabalhos, utilizando dados das empresas brasileiras que são listadas na bolsa de valores (BOVESPA), pois tem mais facilidade para agrupar grande quantidade de dados.

Tabela 2: Tipo de estudo apresentado nos artigos analisados

\begin{tabular}{lcr}
\hline Tipos de estudo & Números de estudos & $\%$ \\
\hline & & \\
Empírico & 26 & 96,30 \\
Teórico & 1 & 3,70
\end{tabular}




\begin{tabular}{lrr}
\hline \hline Total & 27 & 100,00
\end{tabular}

Fonte: Elaborada pelos autores de acordo com os dados obtidos pela pesquisa / 2018 .

A tabela 3 por sua vez demonstra os tipos de gerenciamento de resultados, sendo que o accruals sobressai ao modelo de atividade operacional, observa que os estudos referentes à atividade operacional são escassos e aqueles que usam dos dois tipos são quase nulos.

Tabela 3: Tipos de gerenciamento de resultados - verificado nos estudos empíricos analisados

Tipos de gerenciamento de resultados Números de estudos \%

\begin{tabular}{lcc} 
Accruals & 22 & 81,49 \\
Atividades operacionais & 4 & 14,81 \\
Ambos & 1 & 3,70 \\
\hline \hline Total & $\mathbf{2 7}$ & $\mathbf{1 0 0 , 0 0}$
\end{tabular}

Fonte: Elaborada pelos autores de acordo com os dados obtidos pela pesquisa / 2018.

\subsection{Análises bibliométrica dos artigos}

Nesta, apresenta-se a análise bibliométrica dos estudos em relação ao Gerenciamento de Resultados baseando-se nos artigos selecionados. Na tabela 4, foram selecionados os 10 autores que tem mais publicações e os mais conhecidos em relação ao tema em questão. Destacando-se os quatro autores que mais artigos publicaram sendo eles: Paulo Roberto da Cunha; Roberto Carlos Klann; Edilson Paulo; Gerlando A. S. Franco de Lima, respectivamente quatro; quatro; três e dois artigos publicados, uma vez que esses autores contribuíram com mais de $65 \%$ da produção sobre o tema GR já os seis últimos autores publicaram apenas um artigo durante todo o período analisado.

Tabela 4: Principais autores sobre gerenciamento de resultados 


\begin{tabular}{lcc}
\hline Autores & Publicações & $\%$ \\
\hline CUNHA, P. R. & 4 & 21,07 \\
KLANN, R. C. & 4 & 21,07 \\
PAULO, E. & 3 & 15,78 \\
LIMA, G. A. S. F. & 2 & 10,52 \\
MARTINEZ, A. L. & 1 & 5,26 \\
COSTA, F. M. & 1 & 5,26 \\
CARDOSO, R. L. & 1 & 5,26 \\
FERNANDES, L. B. & 1 & 5,26 \\
MOURA, G. D. & 1 & 5,26 \\
GALDI, F. C. & 1 & 5,26 \\
\hline \hline Total & 19 & 100,00
\end{tabular}

Fonte: Elaborada pelos autores de acordo com os dados obtidos pela pesquisa / 2018.

\section{CONSIDERAÇÕES FINAIS}

O tema Gerenciamento de Resultados no Brasil teve sua primeira publicação feita pelo autor Martinez em 2001 (Gerenciamento de Resultados Contábeis: estudo empírico das companhias abertas brasileiras), e vem despertando interesse em pesquisadores de diversas áreas, sendo um tema polêmico e bastante discutido, uma vez que alguns pesquisadores citam que a utilização do gerenciamento de resultados é considerado como uma fraude e para outros apenas escolhas contábeis facultadas ao gestor.

O principal objetivo foi fazer uma análise sobre as publicações feitas no Brasil sobre o tema gerenciamento de resultados contábeis no periódico escolhido entre 2013 a 2017 . A principal limitação desta pesquisa é relacionada á pouca disponibilidade de publicações sobre o tema, e a falta de livros onde se aprofunda mais as fórmulas usadas no gerenciamento de resultados e suas conclusões.

Os artigos analisados durante o período escolhido, utilizaram em sua maioria estudos empíricos, utilizando dados secundários coletados da BM\&FBovespa, porém não demonstra a real situação do gerenciamento de resultados dentro das empresas brasileiras, até porque não 
são todas que estão listadas na BM\&FBovespa.

Por sua vez o gerenciamento de resultados pelo Accruals foi mais utilizado, demonstrando que há uma falta de exploração com relação às atividades operacionais, assim como é atualmente pelo Accruals.

Ademais, verificou-se que na grande maioria das pesquisas, baseia-se em modelos internacionais como o KS, porque permite extrair as informações diretamente das contas patrimoniais, aplicando-os em dados do mercado de ações brasileiro, deixando de explorar outras formas de investigação e metodologias, onde poderia ampliar os estudos sobre o gerenciamento de resultados no Brasil.

Os resultados obtidos demonstraram que ouve um aumento das pesquisas publicadas nos últimos 3 anos, entretanto concentrou-se mais de $40 \%$ em dois periódicos pesquisados RC\&F (Revista de Contabilidade e Finanças) e RUC (Revista Universo Contábil). Apesar de ter tido um aumento de publicações nos períodos estudados, observa-se que há pouca literatura sobre o tema e a maioria sendo teses, gerando muitas controversas entre os autores, conclui-se que há uma necessidade de mais estudos, para que, futuramente possa ter uma compreensão maior sobre o tema, servindo como base para futuros pesquisadores, os quais possam vir a fazer uma pesquisa baseada na análise de uma empresa que tenha um sistema de gestão de resultados.

Nesse sentido, futuras pesquisas poderiam ser desenvolvidas levando em conta a ética profissional ao utilizar o gerenciamento de resultado, a forma como é utilizado o gerenciamento pelo gestor dentro da empresa e as consequências dessa utilização. Também podendo ser desenvolvido um estudo dentro da empresa em questão ao gerenciamento de resultados por atividade operacionais, pois existe uma carência desse tipo de pesquisa no Brasil.

Por tanto, esta pesquisa contribui para o tema gerenciamento de resultados de forma que possa incentivar e auxiliar futuros pesquisadores da área de contabilidade, em desenvolver novos estudos de forma que possam contribuir para o crescimento e entendimento em relação ao tema gerenciamento de resultados no Brasil, uma vez que esse tipo de estudo ainda é incipiente no pais. 


\section{REFERÊNCIAS}

AMAT. O.; GOWTHORPE, C. Creative Accounting: Nature, Incidence and Ethical

Issues. Journal of Economic Literature, 2004. Disponível em $\leq$ www.ssrm.com>, acesso em 07.09.2018.

CASSEL, C.; SYMON, G. Qualitative research in work contexts. In: CASSEL, C.; SYMON, G. Qualitative methods in organizational research: a practical guide. California: Sage Publications Inc., 1994.

COSENZA, José Paulo; GRATERON, Ivan Ricardo Guevera. A auditoria da contabilidade criativa. Revista Brasileira de Contabilidade, Brasília/DF, ano 32, n.143, p.42-61, set./out.2003.

COELHO, Antonio Carlos; LIMA, Ivan Siqueira. Gerenciamento de Resultados Contábeis no Brasil: Comparação entre Companhias de Capital Fechado e da Capital Aberto. Revista de Administração, v.44, n.3, p.207-221, 2009.

COELHO Carina Martins Porto; NIYAMA Jorge Katsumi ; RODRIGUES Jomar Miranda. Análise da Qualidade da Informação Contábil Frente a Implementação dos IFRS: Uma Pesquisa Baseada nos Periódicos Internacionais (1999 a 2010). Sociedade, Contabilidade e Gestão, Rio de Janeiro, v. 6, n. 2, jul/dez 2011.

COORDENAÇÃO DE APERFEIÇOAMENTO DE PESSOAS DE NÍNEL SUPERIORCAPES. Disponível em: 〈www.capes.gov.br〉. Acesso em: 28.10. 2018.

CPC, Comite de Ponunciamentos Contábeis. CPC 00: Estrutura Conceitual Básica. 2008. Disponível em http://www.cpc.org.br/pdf/pronunciamento_conceitual.pdf. Acesso em 12 Outubro de 2018.

DECHOW, P. M., R. G. SLOAN, and A. P. SWEENEY. Causes and Consequenos off 
Earnings Manipulation: An Analysis off Firms Subject to Enforcement Actions by the SEC. Conten Parary Accounting Research13: p. 1-36, 1996.

FERREIRA, Pedro Lopes. Estatística Descritiva e Inferencial. Faculdade de Economia da Universidade de Coimbra. Coimbra, 2005.

GIL, A. C. Como elaborar projetos de pesquisas. 3. Ed. São Paulo: Editora Atlas, 1996.

GOULART, Andre Moura Cintra. Gerenciamento de Resultados Contábeis em

Instituições Financeiras no Brasil. Universidade de São Paulo, Programa de Pós-Graduação em Contabilidade. São Paulo, 2007.219 p.

IUDÍCIBUS, Sérgio de. Caminhos (e descaminhos) da Contabilidade. Revista de Contabilidade, Conselho Regional de Contabilidade de São Paulo, n.25, p. 32-40,set.2003.

JIRAPORN, P.; MULLER, G.; YOON, S.; KIN, Y. Is earnings management opportunistic or beneficial? An agency theory perspective. International Review of Financial Analysis. v. 17, p. 622-634, 2008.

MACEDO, M. A. da Silva. Mapeamento e análise bibliometrica da utilização da Análise Envoltória de Dados (DEA) em estudo em contabilidade e administração. Contabilidade Gestão e Governança- Brasília, v. 12, n. 3, p. 87-101, set./dez. 2009.

MARIN, Ana Carolina Selbach. Gerenciamento de Resultados: Uma análise dos Resultados das Pesquisas Empíricas no Brasil. Disponível em: https://www.lume.ufrgs.br/bitstream/handle/10183/140591/000965697.pdf?sequence=1. Acesso em 22.09.2018.

MARTINEZ, Antônio Lopo. Gerenciamento de resultados contábeis: estudo empírico das companhias abertas brasileiras. 2001,fls. Tese (Doutorado em Ciências Contábeis), 
departamento de contabilidade e Atuária da Faculdade de Economia, Administração e Contabilidade da Universidade de São Paulo,2001.

MARTINS, Vinicius Gomes; PAULO, Edilson; MONTE, Paulo Aguiar do. O gerenciamento de resultados contábeis exerce influência na acurácia da previsão de analistas no Brasil. Revista Universo Contábil, v. 12, n. 3, p. 73-90, 2016.

MATSUMOTO, Alberto Shigueru; PARREIRA, Enéias Medeiros. Uma pesquisa sobre o Gerenciamento de Resultados Contábeis: causas e consequiências. Revista UnB Contábil UnB, Brasília, vol. 10, no 1, Jan/Jun., 2007.

OLIVEIRA, L. Neutros e neutros. Humanidades, Brasília, v.5, n.10, p.122-127, 1988.

PAULO, Edilson. Manipulação das informações contábeis: uma análise teórica e empírica sobre os modelos operacionais de detecção de gerenciamento de resultados. 2007. 260 f. Tese (Doutorado em Ciências Contábeis) - Curso de Pós-Graduação em Ciências Contábeis, Universidade de São Paulo, São Paulo, 2007.

RODRIGUES, Luiz Fernando. Evidencia de Gerenciamento de Resultados em Ofertas Publicas de Aquisição de Ações de Companhias Abertas: Análise Empírica das Operações Realizadas no Brasil no Período de 2007 a 2012. (Dissertação), Pós-Graduação em Ciências Contábeis, Universidade Federal do Rio Grande do Norte, Brasília, 2013.

RESOLUÇÃO CFC No 1.374/11; NBC TG Estrutura Conceitual para Elaboração e Divulgação de Relatório Contábil Financeiro, QC17. Resoluções e Ementas do CFC.Acesso em: 07.06.2018

ROSA, A.; MENDES, A.; TEIXEIRA, G.; MARTINS, S. Earnings Management no Brasil: uma Análise sob a Perspectiva Sociométrica e Bibliométrica. Revista Contabilidade Vista e Revista, v. 21, n. 4, p. 189-218, 2010. 
SANTOS, Anioval dos; GRATERON, Ivan Ricardo Guevera. Contabilidade criativa e responsabilidade dos auditores. Revista Contabilidade Finanças, USP, São Paulo, n.32, p.722, mai./ago.2003. 